\title{
Tomada de decisão organizacional: analisando o uso de informação por gestores pela via simbólica
}

\author{
Eliane Pawlowski Oliveira Araújo \\ http://orcid.org/0000-0002-5747-8748 \\ I Universidade Federal de Minas Gerais, Belo Horizonte, MG, Brasil. \\ Doutora em Ciência da Informação.
}

http://dx.doi.org/10.1590/1981-5344/4191

A explosão informacional decorrente do desenvolvimento tecnológico tem se consolidado como um desafio para as organizações, principalmente nos processos decisórios, pois ter a informação relevante no momento certo passou de um simples "clichê" a um diferencial competitivo.Entretanto, compreender o processo de tomada de decisão de um gestor envolto nesse contexto pressupõe uma complexidade muito maior que os perfis de competências habituais conseguem expressar. Neste sentido, foi desenvolvido um estudo em nível de doutorado visando compreender as motivações inconscientes que influenciam a dinâmica decisória organizacional tendo como foco o uso de informação para subsidiar a tomada de decisão. Para tanto foram utilizados métodos que abordam as dimensões simbólicas baseados nos pressupostos da psicologia analítica de Carl Jung e nas Estruturas Antropológicas do Imaginário, de Gilbert Durand, para a análise dos conteúdos subjacentes aos comportamentos visíveis de gestores em situação de tomada de decisão estratégica. Buscou-se por esse referencial relacionar, no processo decisório, a forma de percepção da realidade, o enfrentamento da angústia advinda desse processo e a determinação de comportamentos de busca e uso da informação para subsidiar a tomada de decisão. A pesquisa, que consistiu em estudos de casos múltiplos com onze gestores de diferentes organizações, transcorreu no ano de 2017 e teve como instrumentos metodológicos uma entrevista semiestruturada, com a inserção de elementos simbólicos e da técnica do incidente crítico, e posterior aplicação do Teste Arquetípico de Nove Elementos. Foi possível verificar, pela utilização do imaginário como um objeto 
sobre o qual se aplica uma hermenêutica, os aspectos que permeiam os comportamentos visíveis no processo decisório, por meio da identificação dos micro-universos míticos dos gestores e da manifestação criativa presente na narrativa desses sujeitos. Percebeu-se, pela via simbólica, como a informação pode perpassar esse processo e que o campo de estudos de usuários da informação pode se valer de perspectivas oriundas da Antropologia do Imaginário e da Psicologia Analítica para compreender as motivações intrínsecas ao fenômeno informacional e infocomunicacional. Considera-se que a presente pesquisa possibilitou validar o uso de instrumentos alternativos e ratificar a percepção de que o uso de informações vinculadas ao processo decisório organizacional pode ser ampliada para além da perspectiva de modelos comportamentais ou conceitos estáticos. Acredita-se que esta perspectiva pode colaborar para ampliar as fronteiras disciplinares da Ciência da Informação, incorporando novos conceitos ao campo.

Palavras-chave: Tomada de decisões. Informação estratégica. Dimensão simbólico-afetiva. Estruturas Antropológicas do Imaginário. Comportamentos e práticas informacionais.

\title{
Organizational decision taking: analyzing the use of information by managers by the symbolic via
}

\begin{abstract}
The informational explosion resulting from technological development has become a challenge for organizations, especially in decision-making processes, because having the relevant information at the right time has gone from a simple cliché to a competitive edge. However, understanding the decision-making process of a manager involved in this context presupposes a greater complexity than the usual skills profiles can express. In this sense, a study was developed at the doctoral level in order to understand the unconscious motivations that influence the organizational decision-making dynamics, focusing on the use of information to support decision making. For that, we used methods that approach the symbolic dimensions based on the assumptions of Carl
\end{abstract}


Jung's analytical psychology and on Gilbert Durand's Imaginary Anthropological Structures, for the analysis of the contents underlying the visible behaviors of managers in a situation of strategic decision-making. In this referential, we sought to relate, in the decision-making process, the perception of reality, coping with the anguish resulting from this process and the determination of information search and use behaviors to support decision making. The research, which consisted of multiple case studies with eleven managers from different organizations, took place in 2017 and had as methodological instruments a semi-structured interview, with the insertion of symbolic elements and the technique of the critical incident, and subsequent application of the Archetypal Test of Nine Elements. It was possible to verify, through the use of the imaginary as an object on which a hermeneutic applies, the aspects that permeate the visible behaviors in the decision process, through the identification of the mythical micro-universes of the managers and of the creative manifestation present in the narrative of these subjects. It was perceived through the symbolic way how information can permeate this process and that the field of studies of information users can draw on perspectives from the Anthropology of Imaginary and Analytical Psychology to understand the motivations intrinsic to the informational and infocommunicational phenomena. It is considered that the present research made it possible to validate the use of alternative instruments and to ratify the perception that the use of information linked to the organizational decision-making process can be extended beyond the perspective of behavioral models or static concepts. It is believed that this perspective can collaborate to broaden the disciplinary boundaries of Information Science, incorporating new concepts in the field

Keywords: Decision making. Strategic information. Symbolic-affective dimension. Anthropological Structures of the Imaginary. Behaviors and informational practices.

Recebido em 12.11.2019 Aceito em 13.11.2019

\section{Introdução}

Não é exagero afirmar que as possibilidades de acesso à informação, oriundas do desenvolvimento das tecnologias de informação e comunicação no final do século $X X$, revolucionaram a sociedade. Exemplos desse novo cenário podem ser vistos no levantamento realizado 
pelo site da Worldwidewebsize ${ }^{1}$, que mensura o tamanho da Web, que identificou, em março de 2019, a existência de, aproximadamente, 5,8 bilhões de páginas indexadas na rede. No que tange aos aplicativos móveis, o WhatsApp, software desenvolvido para smartphones para troca de mensagens através de uma conexão via internet, atingiu a marca de 1 bilhão de usuários com apenas sete anos de existência ${ }^{2}$. Números gigantescos que tem aumentado exponencialmente a cada ano proporcionando novas formas de relacionamento entre as pessoas e a informação.

No cenário econômico, esse desenvolvimento desencadeou o deslocamento da estrutura, originalmente vinculada a terra e posteriormente a fábrica, para a informação, considerada como ativo intangível essencial para obtenção de êxito nos negócios e responsável por definir as bases de poder do atual contexto sócio-político-econômico global. Essa situação - de relevância da informação no final do último século - foi tão impactante que a Organização das Nações Unidas instituiu, em 2003, a Cúpula Mundial sobre a Sociedade da Informação. Esta ação foi decorrente da preocupação daquela instituição com a consequência da concentração deste "poder informacional" entre as nações hegemônicas - que dominavam os meios de controle e uso da informação (MARQUES, 2012).

No contexto organizacional foi a necessidade de inovar e de se estabelecer estratégias sustentáveis frente ao mercado e à concorrência mundial a responsável pela transformação da informação em insumo fundamental. Esta constatação é destacada por Silva, Campos e Brandão (2005), quando afirmam que as informações são recursos da maior importância para a tomada de decisão nas empresas, bem como por Kennington (1991) que define que a informação (especificamente a Business Information) é necessária à sobrevivência das organizações em um mundo competitivo. Verifica-se, nestas perspectivas, que é fundamental às organizações se adaptarem a esse contexto informacional no desenvolvimento de suas estratégias de negócio, o que pode se dar por meio da implementação de processos de gestão de informação e conhecimento, pelo incremento de ferramentas e de sistemas de recuperação de informação (SRI) e de apoio a decisão (SAD) e, ainda, pela atenção à importância desse recurso no dia a dia organizacional.

Laia (2002) é um dos autores que destacam, nesse cenário, a relevância de se conhecer não apenas sobre os processos, mas também as necessidades informacionais dos indivíduos dentro das organizações, situação considerada por ele como essencial para que uma organização possa assumir uma posição competitiva no mercado. De forma específica, em nível estratégico, isso implica em compreender o comportamento dos gestores em relação às suas demandas de informação, principalmente

1 Dados de 21 de março de 2019. Fonte: http://www.worldwidewebsize.com/

2 Estatística divulgada por Jan Koum, CEO e fundador do WhatsApp acessível pelo endereço https://www.facebook.com/photo.php?fbid=10153874647095011\&set=a. 10150731994525011 .456435.500035010\&type=3\&theater 
aquelas que subsidiam os processos decisórios, cuja efetividade de utilização pode comprometer o desempenho organizacional.

A análise desse cenário, tendo como foco o indivíduo, remete, ainda, à afirmativa de Simon (1979, p. 294) quando este destacou, na década de 1970, que os sistemas de processamento de informação da sociedade contemporânea estão imersos em um mar de dados, mas que o recurso escasso já não é mais a informação, mas sim a capacidade de dar atenção a ela: "a atenção é o principal gargalo na atividade organizacional, e esse gargalo torna-se ainda mais estreito à medida que nos aproximamos do topo das organizações".

Considera-se no cenário acima identificado que, em função da racionalidade limitada ${ }^{3}$, da pressa em decidir $^{4}$ e do excesso de informações disponíveis, os gestores não têm sido tão racionais quanto se pressupõe, deixando, assim, margem para que as decisões sejam tomadas também sob a influência de elementos subjetivos, o que torna o conhecimento destacado por Laia (2002) uma tarefa complexa por envolver não só aspectos visíveis, mas também os inconscientes.

Apesar desta constatação, o que se tem percebido é que as pesquisas desenvolvidas no campo da Ciência da Informação não tem se valido deste viés de análise, o que tem provocado alguns autores, como Paula (2012), Venâncio (2007), Araújo (2013) e Albright (2011) a destacarem a ausência de instrumentos que possibilitem ir além do que tem sido obtido na maioria dos estudos sobre comportamentos e práticas informacionais. Esses autores ressaltam a necessidade de se propor novas perspectivas de estudo visto considerarem que a maioria das teorias sobre o comportamento informacional reflete apenas uma perspectiva cognitiva, na qual se enfoca apenas o papel do pensamento e do sentimento conscientes, mas não consideram as motivações e as emoções subjacentes que estão fora do domínio da consciência.

Uma iniciativa no sentido de abordar o fenômeno informacional sob uma vertente "psicossociológica" começou a tomar corpo por meio dos estudos de Paula (2005) e Araújo (2013) inaugurando uma nova abordagem nos estudos de usuários de informação. Esses estudos, que procuraram destacar a influência das motivações inconscientes no fenômeno infocomunicacional, foram responsáveis por desencadear uma série de pesquisas que procuraram ampliar os vieses investigativos no campo. No rol destas pesquisas ressalta-se o trabalho, que se apresenta a seguir, que buscou compreender as motivações inconscientes que influenciam a dinâmica decisória organizacional tendo como foco o uso de informação para subsidiar a tomada de decisão. Para tanto, a investigação

3Conceito abordado por March e Simon (1972), parte do pressuposto da impossibilidade dos decisores identificarem todas as alternativas disponíveis quando de uma tomada de decisão tendo em vista os "aspectos subjetivo e relativo da racionalidade" envolvidos nos processos decisórios (ARAUJO, 2013, p.12).

4 Este entendimento tem como referência a obra de Nicole Aubert (2003) segundo a qual o tempo está "compactado" e esta relação com o "novo" tempo acaba por desenhar uma sociedade imediatista que vive dentro de uma dinâmica de alta competitividade na qual os indivíduos se sentem obrigados a estarem continuamente presentes abolindo-se desta forma o espaço para reflexão e restando apenas o tempo para a ação. 
realizada utilizou métodos baseados nos estudos da psicologia analítica de Carl Jung e da dimensão simbólica presente nas Estruturas Antropológicas do Imaginário, de Gilbert Durand, visando a análise dos conteúdos subjacentes aos comportamentos visíveis de gestores em situação de tomada de decisão estratégica. Buscou-se relacionar, no processo decisório, a forma de percepção da realidade, o enfrentamento da angústia advinda desse processo e a determinação de comportamentos de busca e uso da informação para subsidiar a tomada de decisão.

O estudo, que será abordado neste artigo, procurou contemplar o desenvolvimento de novas estratégias que permitissem entender os usuários em seus múltiplos aspectos, compreendendo o processo de busca e uso da informação e as necessidades informacionais dos indivíduos nas, e além das, dimensões social, experiencial e contingencial.

\section{A dimensão simbólica como estratégia metodológica}

O incremento da psicologia no âmbito organizacional ocorreu, segundo Zanelli (1994), em razão das pressões acarretadas pelo desenvolvimento industrial. $O$ desenvolvimento desse campo foi responsável por considerar os aspectos ligados aos sentimentos e ao inconsciente do sujeito como aspectos intervenientes no comportamento organizacional, fato que iniciou uma nova tendência de estudos sobre as organizações. Neste sentido, sentimentos e desempenho, motivação e conflitos e suas relações com o imaginário inconsciente, por exemplo, estimularam a percepção da "potencialidade da chamada psicologia profunda como recurso necessário para a plena compreensão do trabalho humano dentro das organizações racionais" (MALVEZZI, 1996, p.7).

Essa forma de investigar as questões relativas à natureza humana direcionada aos comportamentos e as motivações dos indivíduos em um plano inconsciente - tem sua base referenciada, principalmente, nos trabalhos de Sigmund Freud e Carl Jung. Em especial, este último desenvolveu uma corrente de estudos denominada Psicologia Analítica que considera que o inconsciente possui todo o material psíquico que subjaz ao limiar da consciência e que a psique é composta de numerosos sistemas e níveis que, apesar de serem diversificados, são interatuantes e pode ser distinguida em três níveis: a consciência, o inconsciente pessoal e o inconsciente coletivo.

Para Jung (1985), a consciência é a única parte da mente conhecida diretamente pelo indivíduo. Constitui-se como uma película que cobre o inconsciente, cuja extensão é desconhecida apesar de, segundo o autor, um quinto, um terço, ou talvez metade da vida humana se desenrolar em condições inconscientes. Jung (1985), que considera não ser possível lidar com os processos inconscientes devido a sua natureza intangível, o classifica em duas espécies: pessoal e coletivo. Para ele, os conteúdos inconscientes são de natureza pessoal quando se pode reconhecer no passado seus efeitos, sua manifestação parcial ou sua origem específica. São partes integrantes da personalidade e tem fácil acesso à consciência quando necessário. Contêm lembranças perdidas, reprimidas, evocações dolorosas, percepções que, por falta de intensidade, não atingiram a 
consciência. Possui a característica de reunir conteúdos para formar um aglomerado ou constelação (chamada por Jung de complexo).

O inconsciente coletivo, ao contrário, não é fruto das vivências do indivíduo, mas corresponde a um reservatório de "imagens". Na realidade, embora Jung utilize frequentemente essa descrição abreviada, considerase melhor descrevê-lo como a "potencialidade para representar imagens" - padrões estruturadores dessas representações mentais e do psiquismo latentes herdadas de um passado ancestral no qual estão incluídos todos os antecessores (humanos, pré-humanos ou animais). De acordo com o autor, trata-se da camada mais profunda do inconsciente onde estão adormecidos os padrões estruturadores universais e originários dos quais o cérebro humano está impregnado há milênios estando, por esse motivo, no inconsciente de todos e requerendo apenas certas condições para vir a tona. Denominadas inicialmente por Jung (1985a, 2011) como "imagens" são, na realidade, simultaneamente sentimento e pensamento, possuem vida própria e são facilmente encontrados nas expressões dos sistemas filosóficos, gnósticos, religiões e outras formulações apoiados nas percepções do inconsciente como fonte de conhecimento.

Verifica-se, portanto, na perspectiva de Jung, que o inconsciente contém, não só componentes de ordem pessoal, mas também impessoal e coletiva, sob a forma de categorias herdadas (ou arquétipos). Conforme mencionou Guerriero (2001, p. 26)

Acumulamos o saber de nossos ancestrais, reelaboramos esse conhecimento eliminando algumas partes e acrescentando $o$ que descobrimos e inventamos e transmitimos tudo isso a nossos descendentes. Não nos limitamos apenas às nossas experiências, mas através da linguagem simbólica temos acesso também às experiências de nossos semelhantes. A capacidade de simbolização e criação cultural permitiu-nos constituir uma extraordinária característica: pensar no que não está presente diante de nossos olhos. Essa capacidade de abstração e transcendência possibilitou superar as limitações impostas pela natureza.

Eliade (1991) destaca que esse imaginário simbólico pode revelar certos aspectos da realidade, sendo o que auxilia o sujeito a libertar-se fazendo "explodir" a realidade imediata. Conforme ressalta o autor (1991, p.21), os símbolos e os mitos vêm de longe e fazem parte do ser humano, sendo impossível não reencontrá-los "em qualquer situação existencial do homem no Cosmos".

Considera-se, assim, que a faculdade de "significar o mundo" implica em entrar no plano simbólico transformando-se as questões cotidianas por meio da cultura. Esta constatação parte do pressuposto de que por meio do mítico é possível traçar um diagnóstico dos aspectos intrínsecos à sociedade e ao comportamento humano. Esta perspectiva pode ser contemplada por várias abordagens, técnicas e métodos, dentre as quais se destacam as Estruturas Antropológicas do Imaginário, de 
Gilbert Durand ${ }^{5}$. Durand (2012) considera o imaginário como o alicerce sobre o qual são construídas as concepções do indivíduo e da sociedade e que, por seguirem regras estruturais, os mitos podem possibilitar uma hermenêutica. A base da teoria de Durand (2012) parte do princípio de que os símbolos se constelam e se relacionam com os gestos corporais estabelecendo uma representação simbólica, o que permite que o imaginário possa ser utilizado na compreensão de como o homem enfrenta suas angústias originais constituindo-se como uma base antropológica sobre qual se constroem as significações histórica e social. Para o autor, diante da impossibilidade de encarar o desconhecido e manusear os perigos que este possa representar, o imaginário cria imagens buscando desenvolver estratégias para enfrentar as situações que as evoquem. Assim, a imaginação atrai o tempo e a morte a um terreno onde pode vencê-los com facilidade.

O conjunto da obra de Gilbert Durand contempla, dentre várias contribuições ao estudo do imaginário, a elaboração de uma teoria que sistematizou uma classificação dinâmica das imagens e o desenvolvimento de metodologias apoiadas no método crítico do mito. Destaca-se, nessa vertente, o Teste Arquetípico de 9 Elementos (AT.9), de autoria de seu discípulo Yves Durand $(1988,1967)$, que se configura como um instrumento que possibilita compreender como o indivíduo se posiciona frente à angústia existencial e visualiza as ações que o mesmo executa nesse enfrentamento da realidade.

\section{Analisando o uso de informação pela via simbólica}

A fim de compreender os aspectos intrínsecos aos comportamentos visíveis no uso da informação em processos decisórios estratégicos foi realizada uma pesquisa qualitativa explicativa que procurou identificar os fatores que contribuíram para a ocorrência um determinado fenômeno (busca e uso de informação para subsidiar uma decisão estratégica). A estrutura empírica baseou-se em estudos de Du Toit et al (2011), Palmer (1991), Paula (2012) e Araújo (2013) e seu objetivo foi investigar os aspectos inconscientes presentes no comportamento informacional de gestores em situação de tomada de decisão estratégica utilizando, para tanto, o imaginário e a dimensão simbólico-afetiva como base para uma hermenêutica.

\subsection{Da pesquisa}

A investigação compreendeu a análise, em profundidade, de estudos de casos múltiplos que tinham como público-alvo gestores de diferentes organizações. A seleção das unidades de análise foi viabilizada por meio de uma adaptação da técnica Snowball Sampling. Tratou-se de um estudo de caso no qual o comportamento de indivíduos em situação de tomada de decisão foi viabilizado por meio da análise de onze unidades, tendo sido utilizada como estratégia de investigação e análise:

5Antropólogo e sociólogo francês 
- Uma entrevista semiestruturada sobre a história de vida e história profissional dos entrevistados que incluiu uma abordagem baseada na manifestação poética (associação livre de imagens) e a aplicação da Técnica do Incidente Crítico (que contemplou o relato de uma situação que envolveu uma tomada de decisão em nível organizacional que o entrevistado julgou ser estratégica);

- A produção de um desenho e narrativas elaborados com base nos protocolos do AT.9 tendo como referência o episódio relatado no incidente crítico, seguido de entrevista livre na qual os pesquisados dissertaram sobre a estruturação do desenho e do texto;

- A análise do material por meio das Estruturas Antropológicas do Imaginário, de Gilbert Durand e das teorias da psicologia analítica relativa aos testes projetivos.

Neste repertório teórico-metodológico o AT.9, se configurou como um dos instrumentos que possibilitou a leitura do imaginário ao projetar, por meio do simbolismo, situações existenciais do indivíduo. Isto permitiu a compreensão do universo mítico pela "mensagem" composta por símbolos que são dispostos, em princípio, de forma organizada e interrelacionada (OLIVEIRA, 2011). Os protocolos do teste se constituem das seguintes etapas:

a) Elaboração de um desenho com a seguinte instrução: "Componha um desenho com: uma queda, uma espada, um refúgio, um monstro devorador, alguma coisa cíclica (que gira, que se reproduz ou que progride), um personagem, água, um animal (pássaro, peixe, réptil ou mamífero), fogo".

b) Elaboração de uma narrativa por escrito explicando a história do desenho.

c) Resposta a um questionário e preenchimento de um quadro.

A utilização desses métodos e a interpretação do material simbólico obtido na pesquisa procuraram, portanto, identificar indícios que revelassem como se deu o processo de busca e uso de informações para a tomada de decisão.

\subsection{Dos resultados}

Os gestores entrevistados se relacionaram a diferentes ramos da atividade econômica e possuíam perfis heterogêneos. A fim de exemplificar a aplicação do AT.9 na pesquisa apresenta-se, a seguir, a estruturação feita pelo entrevistado E1 (Figura 1) que foi baseada no incidente crítico apresentado no Quadro 1:

Quadro 1. Incidente crítico relatado

\begin{tabular}{l|l}
\hline \multicolumn{1}{c|}{ Decisão estratégica narrada } & \multicolumn{1}{c}{ Aspecto crítico envolvido no processo } \\
\hline $\begin{array}{l}\text { Investimento de recursos na construção de } \\
\text { uma nova área dentro da empresa }\end{array}$ & $\begin{array}{l}\text { A decisão equivocada poderia gerar um prejuízo financeiro de } \\
\text { milhões para a empresa e ameaçar o cargo ocupado }\end{array}$ \\
\hline
\end{tabular}

Fonte: Adaptado de Araújo (2017, p.178) 
Figura 1. Desenho elaborado por E1 com base no incidente crítico

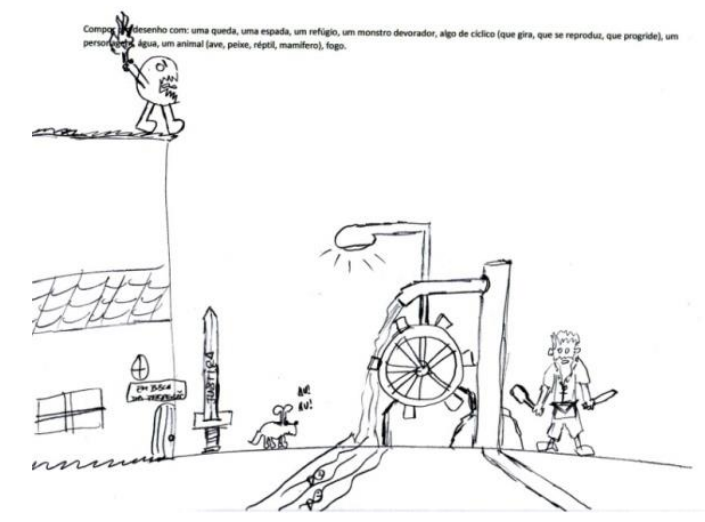

Fonte: Araújo (2017, p.179)

A narrativa sobre o desenho feito pelo entrevistado foi:

\begin{abstract}
"Pensei em eu trabalhando como um mestre construtor, que desenvolvia e inovava dentro do meu ambiente para propiciar os melhores resultados e condições de vida para todos, ainda tendo que estar sempre alerta e sob a proteção de Deus, para se necessário, defender com a espada da justiça os monstros que sempre querem destruir tudo com fogo! Sempre sendo tudo para alcançar estar feito por completo a busca da perfeição!"
\end{abstract}

Pela análise estrutural, que possibilita determinar a estrutura do imaginário, verificou-se que os elementos ansiógenos do teste (monstro e queda) se apresentam em funções diferentes: a queda, representada pela queda d'água, tem sua função eufemizada pelo sentido da força que movimenta e gera a luz. Em contraposição, o monstro, representado por um monstro com uma tocha na mão, personifica uma ameaça. O personagem tem ferramentas em suas mãos para criar algo novo, já que a espada da justiça é quem protege contra o que o aflige. $O$ combate não é visível no desenho, mas é referenciado na narrativa: "defender com a espada da justiça os monstros que querem destruir tudo com fogo". Assim, apesar das associações positivas (luz, justiça, vida), não há um cenário unicamente pacífico porque o monstro constitui uma ameaça. Os outros elementos complementares (água, fogo e animal) potencializam os dois cenários criados, sendo que o animal parece ser a ligação entre esses dois mundos que ocorrem de forma simultânea (pois enquanto 0 personagem constrói, o monstro espreita), estando o refúgio de um lado e o elemento cíclico de outro. Este tipo de construção remete a dois cenários - um ameaçador e outro bucólico, com peixes nadando em um córrego - o que dá indícios de que o micro-universo de E1 pertence ao regime noturno e se caracteriza como Micro-universo do dualismo cujo espaço é dividido em opostos que abrigam conjuntos míticos portadores de dualismo. O entrevistado se integra nos dois cenários, tanto pela coragem contida na espada, quanto pela atitude construtiva do personagem. 
Trazendo a análise para o aspecto informacional, verifica-se que não houve uma alusão direta simbólica sobre o uso de informação para subsidiar a decisão tomada por E1. Pela estruturação do desenho, contudo, é possível inferir que a presença de ferramentas sendo utilizadas pelo personagem pode ser associada à informação como instrumentos utilizados pelo entrevistado para construir sua decisão. Esta alusão é facultada pela associação ao conteúdo da fala de E1 na entrevista, pois foi por meio do seu conhecimento do sistema de financiamento, da dinâmica do governo no processo, da sua análise do custo-benefício sobre o que seria a decisão mais acertada e o conhecimento também dos riscos envolvidos, que E1 baseou sua decisão. Essas foram as "ferramentas" que o entrevistado utilizou para decidir, entendimento que se coaduna com a perspectiva de que a informação se manifesta sob várias formas no cotidiano e na trajetória do indivíduo, não se constituindo obrigatoriamente no ambiente organizacional, em uma fonte única, sendo, assim, atemporal e polimorfa.

As inferências que essas constatações possibilitaram deixaram algumas indagações para investigações futuras sobre as razões que motivam a escolha por determinadas informações em detrimento de outras. Assim, considerando um gestor que possui um perfil mítico do tipo Dualismo, como E1: a) cujo micro-universo é caracterizado pelo espaço estruturado e por aspectos opostos e contraditórios; b) cuja ação visa gerar vida sendo o sujeito movido/inspirado pela ponderação no agir; e c) para quem, simbolicamente, a informação pode ser representada pela ação do personagem através de uma ferramenta - será que a escolha (ou seleção intuitiva, inconsciente) de informação para a tomada de decisão recai em informações que permitam ao sujeito a criação de coisas novas e abertura para novas possibilidades? A informação vista como uma "ferramenta" pode ser associada ao sentido de possibilitar a criação de algo?

\section{Considerações finais}

As Estruturas Antropológicas do Imaginário tem como objetivo decifrar o sentido próprio da realidade humana, em oposição aos métodos "explicativos" que procuram apenas estabelecer as relações de causaefeito. Da mesma forma, o AT.9, por ser um instrumento que possibilita a leitura do imaginário ao projetar, por meio do simbolismo, situações existenciais do indivíduo, permite a realização de um diagnóstico capaz de descrever a interação do sujeito com a estrutura simbólica na qual ele se insere. Essa identificação possibilita a construção de inferências sobre as motivações que agem como pano de fundo nos processos de tomada de decisão considerando como cada indivíduo se posiciona no enfrentamento das angústias às quais estão sujeitos. Isso ocorre porque, de acordo com Bouchard (1996, p.258), "mais do que sapiens, o homem é symbolicus" e a estrutura simbólica pode ser identificada em vários contextos e civilizações, o que possibilita que o simbolismo seja utilizado como estudo interpretativo devido ao fato dos símbolos, mitos e ritos constituírem formas de expressão de padrões básicos de experiência. 
Nesta perspectiva, os mitos e símbolos ao serem aplicados à leitura da psicodinâmica dos membros das subculturas e dos valores "tribais" de uma organização, podem contribuir para a compreensão dos esforços dos indivíduos para significar o mundo ao seu redor, auxiliando na interpretação de diversos fatores inerentes à organização, dentre os quais se destacam a cultura organizacional e o comportamento informacional. (CHANLAT, 1996; PAULA, 1999; KRECH et al, 1975). Na análise do resultado da pesquisa ora apresentada, foi observado que trabalhar nessa dimensão possibilitou perceber que as informações utilizadas pelos gestores entrevistados não estavam prontas, esperando para serem usadas e não se relacionaram a lacunas. Foram coletadas no trajeto profissional, no olhar às vezes direcionado, mas, outras vezes, despretensioso e nem sempre consciente.

Nesse sentido, aponta-se para uma reflexão acerca do comportamento informacional, partindo-se do pressuposto de que o conceito deste termo [comportamento] está relacionado a um aspecto permeado pelo entendimento de que há uma necessidade que move o sujeito em direção a uma ação de busca e uso. O que se percebeu pelos relatos dos entrevistados é que, na atividade gerencial, nem sempre ocorrerão situações em que a tríade necessidade-busca-uso será a motivadora do fenômeno informacional. Para a questão: "Preciso tomar uma decisão e qual informação vou usar para balizar a ação?", deve-se observar que há situações em que a informação já foi internalizada pela vida cotidiana, histórica e social e não será recuperada de algo externo, consultável por aquela ocasião. Os seres humanos apreendem e usam informação de uma forma incorporada à sua vida, da mesma forma como respiram. Trazem consigo a informação oral, a dos processos comunicativos, a apreendida pela percepção, a absorvida por meio de relatórios, a do rádio ligado pelo vizinho, a que os olhos buscam nos outdoors... o ser humano está rodeado de informação e nem sempre essa relação pode ser expressa em formulas matemáticas.

A Ciência da Informação ainda tem olhado a informação em partículas. Em virtude de posicionamentos conceituais, ela tem sido etiquetada sob várias denominações e abordagens. É preciso, entretanto, deixar entreaberto um espaço para compreendê-la em sua integralidade. Assim, como afirma Gilbert Durand (2010, p.118 ), "a imagem 'enlatada' anestesia aos poucos a criatividade individual da imaginação", deve-se cuidar para que a informação não seja percebida apenas em um formato "enlatado", principalmente nos ambientes organizacionais, nos quais a sua característica atemporal, polimorfa, multivocacional a situa além das bases de dados, relatórios de desempenho e sistemas de apoio a decisão

\section{Referências}

ALBRIGHT, K. S. Psychodynamic perspectives in information behaviour. Information Research, v. 16, n. 1, paper 457. 2011. Disponível em http://InformationR.net/ir/16-1/paper457.html. Acesso 05 fev. 2019. 
ARAUJO, E. P. O.Tomada de decisão organizacional e subjetividade: análise das dimensões simbólico-afetivas no uso da informação em processos decisórios. Dissertação (Mestrado em Ciência da Informação) Escola de Ciência da Informação, Universidade Federal de Minas Gerais. Belo Horizonte. 2013.

ARAUJO, E. P. O. Comportamento informacional em processos decisórios estratégicos: dimensão simbólica do uso da informação por gestores. Tese. Universidade Federal de Minas Gerais 2017

AUBERT, N. Le Culte de L'Urgence: La société malade du temps. Paris: Flammarion, 2003

BOUCHARD, S. Simples símbolo: eficácia prática dos sistemas simbólicos da organização. In: CHANLAT, J. F.O indivíduo na organização: dimensões esquecidas. São Paulo: Atlas, 1996

CHANLAT, J.F. O indivíduo na organização: dimensões esquecidas. 3. ed. São Paulo: Atlas, 1996

DU TOIT, D.; VELDSMAN, T.; VAN ZYL, D. The testing and validation of a model for leadership maturity based on Jung's concept of individuation.2011.Disponível em: http://www.academicconferences.org/pdfs/ecmlg2011 best phd paper.pdf. Acesso em: 30 nov. 2019.

DURAND, G. O imaginário: ensaio acerca das ciências e da filosofia da imagem. Rio de Janeiro: Difel, 2010

DURAND, G. As estruturas antropológicas do imaginário. São Paulo: Martins Fontes, 2012.

DURAND, Y. Elementos de utilização prática e teórica do Teste AT.9. Annales du Centre d'Enseignement Supérieur de Chambéry, n.5, 1967

DURAND, Y. L'exploration de L'imaginaire: Introduction à La modélisation dês Univers Mythiqués. Paris: L'espacebleu, 1988.

ELIADE, M. Imagens e símbolos. São Paulo: Martins Fontes, 1991.

GUERRIERO, S. As origens do antropos. In: GUERRIERO, S.; RIBAS, J.B.C.; KEMP, K.; PASSADOR, L.H.; FERRARI, M.D. Antropos e Psique: o outro e sua subjetividade. São Paulo: Olho d'água, 2001.

JUNG C.G. Fundamentos de psicologia analítica. Petrópolis: Vozes, 1985.

JUNG, C.G. Psicologia do inconsciente. Petrópolis: Vozes, 1985a.

JUNG, C.G. Os arquétipos e o inconsciente coletivo. 7 ed. Petrópolis: Vozes, 2011.

KENNINGTON, D.The marketing of public-sector business information service. In: MASON, D. Information for industry: twenty-one years of the Library Association Industrial Group. London: Library Association Publishing, 1991. 
KRECH, D.; CRUTCHFIELD, R. S.; BALLACHEY, E. L. O Indivíduo na sociedade: um manual de psicologia social. São Paulo: Pioneira, 1975.

LAIA, M. M. Comportamento de busca de informações de gerentes e técnicos em uma instituição governamental: um estudo de caso.

Dissertação. Mestrado. Escola de Ciência da Informação.Universidade Federal de Minas Gerais. 2002.

MALVEZZI, S. Prefácio. In: ZIEMMER, R. Mitos organizacionais. São Paulo: Atlas, 1996.

MARCH, J. G.; SIMON, H. A. Teoria das Organizações. 2. ed. Rio de Janeiro: Fundação Getúlio Vargas, 1972.

MARQUES, L. E. A cúpula mundial sobre a sociedade da informação CMSI: foco nas políticas de informação. Dissertação. Escola de Ciência da Informação. Universidade Federal de Minas Gerais. 2012.

OLIVEIRA, E. R. Dimensões culturais no tratamento do câncer bucomaxilofacial. Tese. Universidade Federal de Pernambuco. 2011.

PALMER, J. Scientists and information: I. Using cluster analysis to identify information style. Journal of Documentation, v. 47, 105-226, 1991.

PAULA, C. P. A. Informação e psicodinâmica organizacional: um estudo teórico. Dissertação Mestrado. Escola de Ciência da Informação. Universidade Federal de Minas Gerais. Belo Horizonte, 1999.

PAULA, C.P.A O símbolo como mediador da comunicação nas organizações: uma abordagem junguiana das relações entre a dimensão afetiva e a produção de sentido nas comunicações entre professores do departamento de psicologia de uma instituição de ensino superior brasileira. Tese (doutorado) - Instituto de Psicologia da Universidade de São Paulo. 2005.

PAULA, C. P. A. Proposta de metodologia para a investigação do comportamento de busca informacional e do processo de tomada de decisão dos líderes nas organizações: introduzindo uma abordagem clínica na informação. XIII ENANCIB. Rio de Janeiro, 2012.

SILVA, A.B.O.; CAMPOS, M.J.O.; BRANDÃO, W.C. Proposta para um esquema de classificação das fontes de informação para negócio. Datagramazero, v. 6, n. 5, out 2005.

SIMON,H. Comportamento administrativo: estudo dos processos decisórios nas organizações administrativas. Rio de Janeiro: Fundação Getúlio Vargas, 1979.

ZANELLI, J.C. Movimentos emergentes na prática dos psicólogos brasileiros nas organizações de trabalho: implicações para a formação. In: CONSELHO FEDERAL DE PSICOLOGIA. Psicólogo Brasileiro: Práticas Emergentes e Desafios para a Formação. São Paulo: Casa do Psicólogo, 1994 
VENANCIO, L. S. O caminhar faz a trilha: o comportamento de busca da informação sob o enfoque da cognição situada. Dissertação. (Mestrado). Escola de Ciência da Informação. Universidade Federal de Minas Gerais. Belo Horizonte, 2007. 